\title{
Paraganglioma in the bladder: a case report
}

\author{
Genta Iwamoto², Takashi Kawahara" ${ }^{*}$ (D, Mikiko Tanabe², Sahoko Ninomiya², Daiji Takamoto², Taku Mochizuki², \\ Shinnosuke Kuroda², Teppei Takeshima², Koji Izumi ${ }^{2}$, Yusuke Hattori ${ }^{2}$, Jun-ichi Teranishi², Yasushi Yumura², \\ Yasuhide Miyoshi ${ }^{2}$ and Hiroji Uemura ${ }^{2}$
}

\begin{abstract}
Background: Paraganglioma is an extra site of pheochromocytoma. Paraganglioma in the bladder is a very rare disease accounting for $0.06 \%$ of all bladder tumors.

Case presentation: A 77-year-old Japanese man was referred to our department for the further examination of a bladder tumor detected on preoperative computed tomography of his gastric cancer. Cystoscopy revealed a submucosal tumor in the upper area of his bladder, so transurethral resection of the bladder tumor was performed. During transurethral resection of the bladder tumor, his blood pressure sharply increased, and a pathological examination showed paraganglioma in his bladder. Postoperative I-123-metaiodobenzylguanidine scintigraphy detected a higher intake of his bladder tumor. Laboratory examinations showed a slightly increased noradrenaline level of $530 \mathrm{pg} / \mathrm{ml}$ and reduced platelet count at 167,000/ $\mathrm{LL}$. Based on the progression of his gastric cancer, no additional therapy was performed on his bladder tumor. Eight months after surgery, he died from aspiration pneumonitis.
\end{abstract}

Conclusions: Here we report a rare case of paraganglioma in the bladder. We discuss paraganglioma based on previous studies.

Keywords: Paraganglioma, Bladder tumor, Hypertension

\section{Background}

Paraganglioma is an extra site of pheochromocytoma from the adrenal gland. Paraganglioma is reported to account for $18 \%$ of pheochromocytomas, and $10 \%$ of cases occur in the bladder. Paraganglioma in the bladder is a very rare disease and accounts for $0.06 \%$ of all bladder tumors [1-4].

We performed transurethral resection of bladder tumor (TUR-Bt) on a mass unexpectedly detected on preoperative computed tomography (CT) of a patient's gastric cancer, and his arterial blood pressure was abnormally elevated during the procedure. Postoperatively, the tumor was diagnosed as paraganglioma. Here we report a rare case of paraganglioma in the bladder.

\footnotetext{
*Correspondence: kawahara@yokohama-cu.ac.jp; takashi_tk2001@yahoo.co.jp ${ }^{1}$ Departments of Urology and Renal Transplantation, Yokohama City University Medical Center, Yokohama, Japan

Full list of author information is available at the end of the article
}

\section{Case presentation}

A 77-year-old Japanese man was referred to our department for treatment of a bladder mass $(26 \mathrm{~mm}$ in diameter) detected on preoperative $\mathrm{CT}$ of his gastric cancer. He had no remarkable medical history except for gastric cancer and hypertension. The stage of gastric cancer was T1b(SM)N0M0. A laboratory examination showed almost normal values except for a low platelet count of $167,000 / \mu \mathrm{L}$. Urinary cytology showed class II. A CT revealed a 26$\mathrm{mm}$ bladder tumor in the upper region of his bladder (Fig. 1). Cystoscopy showed a non-papillary broad-base tumor surrounded by smooth bladder mucosa (Fig. 2). Magnetic resonance imaging (MRI) suggested muscle invasive bladder cancer with low intensity on T1-weighted and T2-weighted imaging (WI) but high intensity on diffusion-weighted imaging (DWI; Fig. 3). 


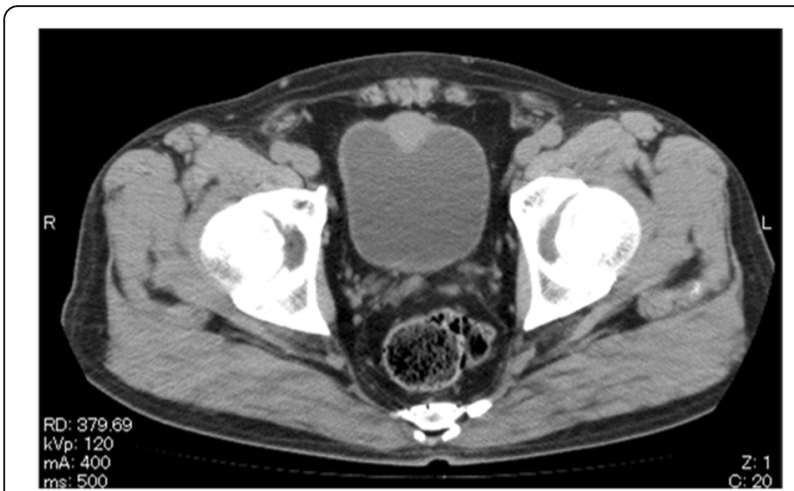

Fig. 1 Computed tomography imaging findings of the bladder
CD56. Only a few tumor cells showed positive immunolabeling for Ki67. Based on these findings, the pathological examination revealed paraganglioma in his bladder. I-23-metaiodobenzylguanidine (MIBG) scintigraphy showed the residual tumor, but no other uptake was observed (Fig. 5). His serum noradrenaline levels were slightly elevated at $530 \mathrm{pg} / \mathrm{mL}$, but both serum and urine catecholamine showed normal values. Careful observation or partial cystectomy was considered an option for this case because of the lack of muscle invasion by the bladder tumor and pathological results. Although he was scheduled to receive partial cystectomy, he died 8 months after TUR-Bt due to aspiration pneumonitis.

Based on these findings, TUR-Bt was performed for his bladder tumor. His usual blood pressure was around $120 / 80 \mathrm{mmHg}$ with olmesartan medoxomil/ azelnidipine intake. At the time of starting transurethral resection (TUR), his blood pressure was elevated as $240 \mathrm{mmHg}$ in his systolic blood pressure. In the procedure of TUR, no active bleeding was observed.

Hematoxylin and eosin staining showed (Fig 4) polygonal tumor cells with finely granular cytoplasm were present in the submucosa. Mitotic figure was inconspicuous. An immunohistochemical study revealed negative findings for cytokeratins and positive findings for chromogranin A, synaptophysin, and

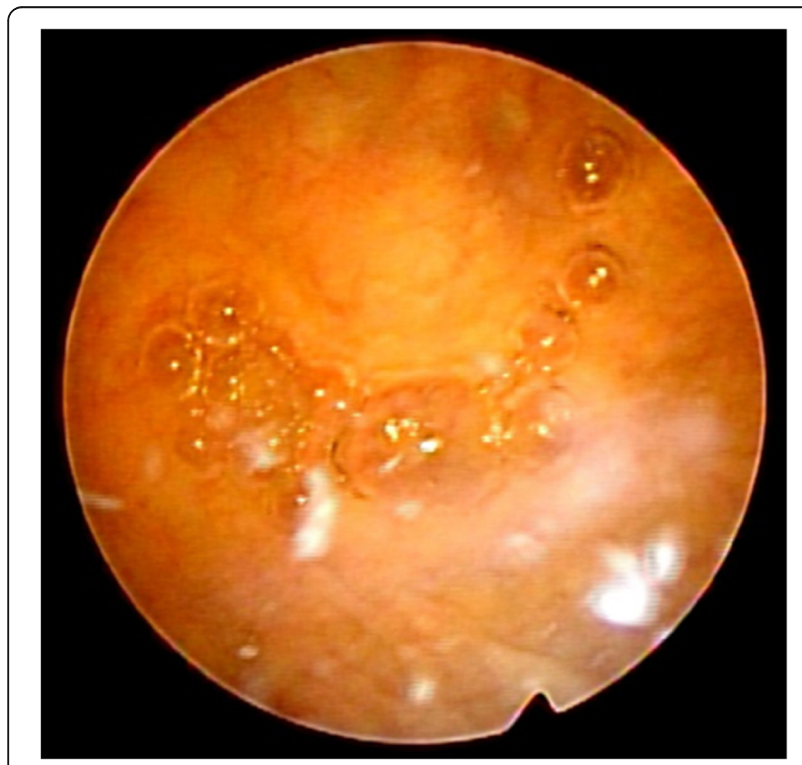

Fig. 2 Cystoscopy image. The tumor was covered with urothelial membrane

\section{Discussion}

Paraganglioma is a rare neuroendocrine neoplasm which tends to develop in the extra-adrenal glands. Paraganglioma in the bladder is extremely rare and accounts for $0.06 \%$ of all bladder tumors $[1,2]$.

Das et al. reported that the symptoms of paraganglioma in the bladder were macroscopic hematuria, hypertension, and hypertension seizure at urination [5]. Yamamoto et al. examined 234 Japanese cases and found that $41.3 \%$ had macroscopic hematuria, 33.2\% hypertension, and $23.0 \%$ hypertension seizure at urination. Only $1.4 \%$ showed all three symptoms, and $10.6 \%$ showed none of these symptoms [6]. The present case showed only hypertension.

MRI and MIBG scintigraphy have been reported useful for a diagnosis. In a previous report, MRI T1WI showed low intensity, while T2-WI showed high intensity, but not all cases show this pattern [7]. In fact, the present case showed low intensity on both T1-WI and T2-WI.

Regarding laboratory findings, $88 \%$ of cases of paraganglioma show elevated levels of urine metanephrine and serum catecholamine $[8,9]$. In bladder paraganglioma, more than $60 \%$ of cases show elevated levels of urine vanillylmandelic acid or serum catecholamine. Despite these high rates of elevation, a differential diagnosis is sometimes difficult because some cases do not show such elevation [5]. In fact, in the present case, catecholamine was not elevated. As such, the preoperative diagnosis is thought to be difficult in cases of bladder paraganglioma. In a previous study, $28.9 \%$ of cases of bladder paraganglioma were diagnosed before surgery, and $61.6 \%$ were initially suspected to be bladder tumor or intramucosal bladder tumor [6]. In the present case, the extremely elevated blood pressure during resection and the pathological findings helped us to arrive at the final diagnosis of bladder paraganglioma. 


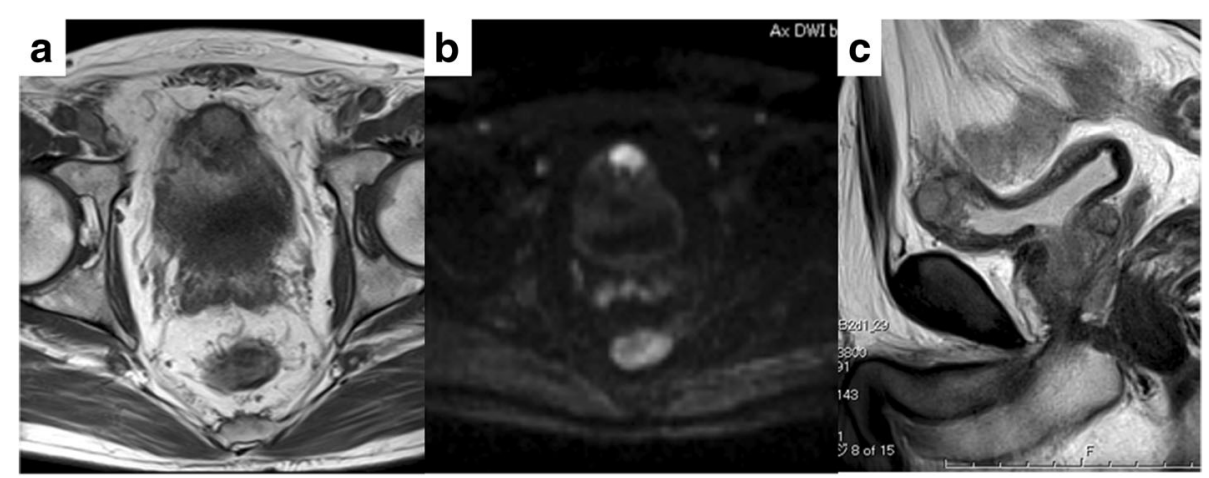

Fig. 3 Magnetic resonance imaging in a axial T1-weighted imaging, $\mathbf{b}$ axial diffusion, and $\mathbf{c}$ sagittal T2-weighted imaging

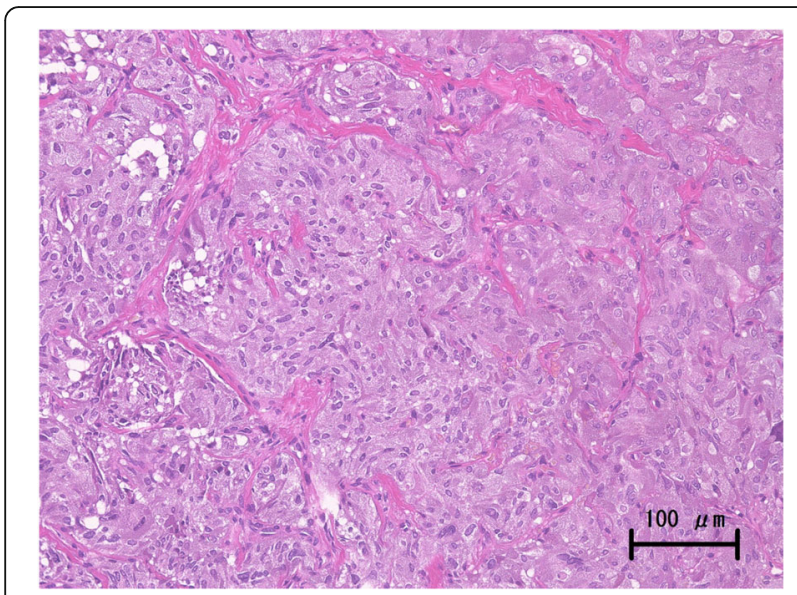

Fig. 4 Hematoxylin eosine staining
Paraganglioma in the bladder can be benign or malignant, but its histopathological diagnosis is difficult. The diagnosis of benign or malignant status depends on the degree of invasion, lymph node metastasis, and distant metastasis. Our patient had T1b(SM)N0M0 gastric cancer and no previous study showed a correlation between gastric cancer and paraganglioma. Partial cystectomy has been recommended, but TUR-Bt might be an option in cases in which the tumor has not invaded the surrounding fat $[10,11]$.

\section{Conclusions}

We describe the case of a patient whose blood pressure became extremely elevated during TUR-Bt, and a pathological examination showed paraganglioma of the bladder. Here we report a rare case of paraganglioma in the bladder.

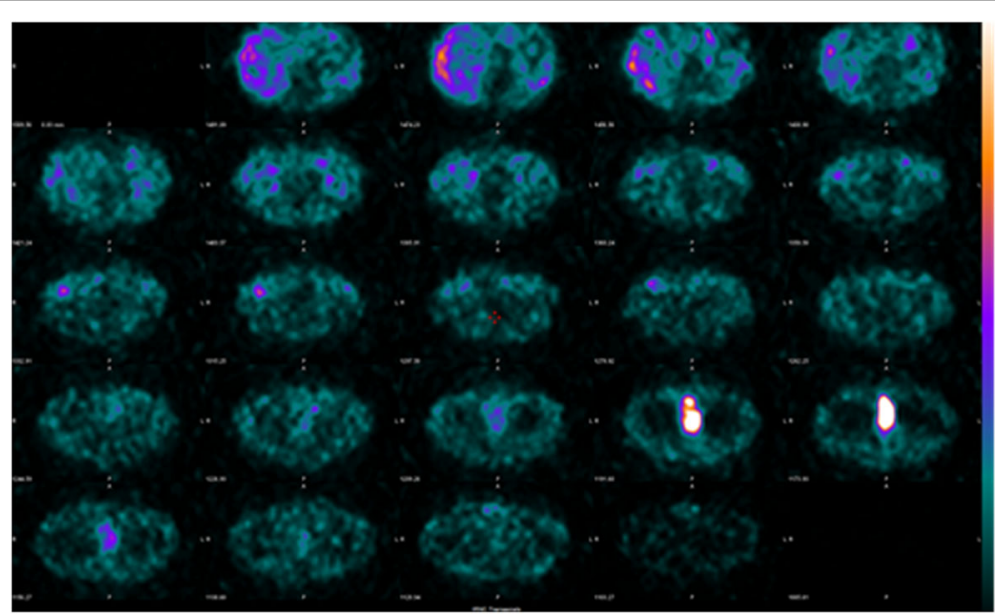

Fig. 5 Metaiodobenzylguanidine scintigraphy 


\section{Acknowledgements}

Not applicable.

\section{Funding}

Grants from KAKENHI grants (16K20152) from the Ministry of Education, Culture, Sports, Science and Technology of Japan and grant for 2016-2017 Research Development Fund (Nos. WJ2810) of Yokohama City University.

\section{Availability of data and materials}

Due to ethical restrictions, the raw data underlying this paper are available from the corresponding author upon request.

\section{Authors' contributions}

Conceived and designed the experiments: Gl, TK, MT, and YH. Analyzed the data: Gl, TK, and MT. Performed the experiments: MT, SN, DT, TM, SK, TT, KI, YH, JT, YY, YM, and HU. Wrote the paper: GI, TK, and MT. All authors read and approved the final manuscript.

\section{Ethics approval and consent to participate}

The present study was approved by the Institutional Review Board (IRB) of Yokohama City University Medical Center.

\section{Consent for publication}

Written informed consent was obtained from the patient for the publication of this case report and any accompanying images. A copy of the written consent is available for review by the Editor-in-Chief of this journal.

\section{Competing interests}

The authors declare that they have no competing interests.

\section{Publisher's Note}

Springer Nature remains neutral with regard to jurisdictional claims in published maps and institutional affiliations.

\section{Author details}

${ }^{1}$ Departments of Urology and Renal Transplantation, Yokohama City University Medical Center, Yokohama, Japan. ${ }^{2}$ Division of Diagnostic Pathology, Yokohama City University Medical Center, Yokohama, Japan.

Received: 20 July 2017 Accepted: 24 September 2017

Published online: 31 October 2017

\section{References}

1. Leestma JE, Price Jr EB. Paraganglioma of the urinary bladder. Cancer. 1971; 28(4):1063-73

2. Kimura NCC, DeLellis RA, Epstein JI, Gill A, Kawashima A, Koch CA Komminoth P, Lam AKY, Merino MJ, Mete O, Apathomas TG, Sadow P, Thompson LDR, Tischler AS, Williams MD, Young WF. Extra-adrenal paragangliomas. In: WHO classification of tumours of endocrine organs. 4th ed. Lyon: WHO Press; 2017.

3. Kojima T, Kawai K, Tsuchiya K, Abe T, Shinohara N, Tanaka T, Masumori N, Yamada S, Arai Y, Narita S, et al. Identification of a subgroup with worse prognosis among patients with poor-risk testicular germ cell tumor. Int J Urol. 2015;22(10):923-7.

4. Nakamura T, Oishi M, Ueda T, Fujihara A, Nakanishi H, Kamoi K, Naya Y, Hongo F, Okihara K, Miki T. Clinical outcomes and histological findings of patients with advanced metastatic germ cell tumors undergoing postchemotherapy resection of retroperitoneal lymph nodes and residual extraretroperitoneal masses. Int J Urol. 2015;22(7):663-8.

5. Das S, Bulusu NV, Lowe P. Primary vesical pheochromocytoma. Urology. 1983;21(1):20-5.

6. Yamamamoto, Y. Shigeaki nakazawa: paraganglioma of the urinary bladder managed by transurethral resection: a case report. Jpn J Urol Surg. 2013; 26(2):231-4.

7. Wong-You-Cheong JJ, Woodward PJ, Manning MA, Sesterhenn IA. From the Archives of the AFIP: neoplasms of the urinary bladder: radiologicpathologic correlation. Radiographics. 2006;26(2):553-80.

8. Whalen RK, Althausen AF, Daniels GH. Extra-adrenal pheochromocytoma. J Urol. 1992;147(1):1-10.
9. Nakajima A, Ide H, Kitamura K, Muto S, Yamaguchi R, Horie S. Rare case of temporally spontaneous regression of retroperitoneal paraganglioma. Int $J$ Urol. 2015;22(4):421-2.

10. Gyftopoulos K, Perimenis P, Ravazoula P, Athanassopoulos A, Barbalias GA. Pheochromocytoma of the urinary bladder presenting only with macroscopic hematuria. Urol Int. 2000;65(3):173-5.

11. Huang KH, Chung SD, Chen SC, Chueh SC, Pu YS, Lai MK, Lin WC. Clinical and pathological data of 10 malignant pheochromocytomas: long-term follow up in a single institute. Int J Urol. 2007;14(3):181-5.

\section{Submit your next manuscript to BioMed Central and we will help you at every step:}

- We accept pre-submission inquiries

- Our selector tool helps you to find the most relevant journal

- We provide round the clock customer support

- Convenient online submission

- Thorough peer review

- Inclusion in PubMed and all major indexing services

- Maximum visibility for your research

Submit your manuscript at www.biomedcentral.com/submit 